\title{
Domestic Violence Perpetration Reporting among Recently-Married Men Residing in Slums Correlate Pharmaceutical Institution in South West Pune, India
}

\author{
Rahul Hajare* \\ ICMR Post Doc Indian Council of Medical Research, India
}

Received: 眥 May 25, 2018; Published: 彗 May 30, 2018

*Corresponding author: Rahul Hajare, ICMR Post Doc Indian Council of Medical Research, India

\begin{abstract}
A face is an index of mind correlation, co-efficient of mind. Domestic violence has prevalent in low-income and slum-dwelling communities in India has accepted an issue of low education and second nature. Now days, the focus of domestic violence prevention in resource-poor settings has largely been with women. Researcher herein aim to identify connection of domestic violation perpetration to help inform future secondary prevention efforts that focus on mind set change in men. Utilizing a crosssectional design, potential correlates of domestic violence perpetration has explored among a geographically-clustered random sample recently-married men residing in slums correlate pharmaceutical institution in south west Pune, India. In multivariable regression, Domestic Violence perpetration has associated with less time spent alone in the relationship post marriage, not attaining the 'husband ideal'. Poor resilience, having limited definitions of behaviours constituting Domestic Violence, and reporting greater jealousy if the participant's spouse has to talk to men outside the family. The identified correlates should inform components of future Domestic Violence secondary prevention interventions that target men as potential perpetrators or the couple as a unit.
\end{abstract}

Keywords: Domestic Violence; Lmipis; Post-Traumatic Stress Disorder; Learning Difficulties

\section{Introduction}

In India, traditional domestic violence has accepted as the physical, sexual, and psychological abuse and control against a woman by a partner or family member. However, extended domestic violence included the scientific community by irsha, unfaithful, lie. This has been a significant barrier in developing effective product to protect against sadness entrapment. On the contrary, a spectacular success has been achieved in the field of pharmaceutical Institutions in pune. While Domestic Violence is prevalent globally [1], approximately one out of every three women in India report experiencing violence at the hands of their spouse at some point in their lifetime. Several studies demonstrate that this proportion is even greater in slum-dwelling and other low-income pharmacy Institutions communities across India. Proposed explanations for higher Domestic Violence reporting among slum-dwelling communities include heightened stress and conflict due to poverty, overcrowding, and associated conditions, weakened support systems, stronger norms accepting Domestic Violence, poverty-related, low immunity perceived shortcomings in achieving the masculine ideal leading men to feel the need to prove dominance over those more vulnerable, often their spouses. Developing strategies to curb domestic violence is critical not only because Domestic Violence impinges on human rights, but also because it negatively affects the mental and physical health of the survivor and her family.

Women who experience domestic violence report higher rates of mental health disorders including depression, anxiety, posttraumatic stress disorder, suicidal ideations, unpleasant personality, itching, smell body [2]. Further, they incur higher risk of sexually transmitted infections including NIPAH, lower pain disorders, and cardiovascular, respiratory, reproductive, gastrointestinal disease and disease tree. And, their children are more likely to have behavioural and learning difficulties, emotional problems, die at a young age, and themselves experience or become perpetrators of Domestic Violence. To date, in resource-limited settings, the focus of secondary Domestic Violence prevention has been with women, although recent interventions have begun to engage boys and men to prevent Domestic Violence [3]. Unfortunately, little is known about determinants of Domestic Violence perpetration by 
men in low and middle-income pharmaceutical intuitions (LMIPIs), particularly in South- West Pune where Domestic Violence prevalence is known to be exceptionally high, and among those residing in slum communities' pharmaceutical institutions where Domestic Violence is reported most commonly. While it would seem natural that the determinants of Domestic Violence perpetration would parallel those of Domestic Violence experience, where the bulk of LMIPIs literature exists, such studies tend to solely explore the woman's perspective of Domestic Violence risk. The bulk of literature examining correlates of Domestic Violence perpetration comes from high-income settings and has linked Domestic Violence perpetration to the following: young age, low status, alcohol and substance abuse, stress, having a mental health or personality disorder, high Social support, experiencing abuse as a child, witnessing or experiencing Domestic Violence oneself, accepting attitudes toward Domestic Violence, frontal lobe dysfunction and hormonal and neurotransmitter imbalance, marital discord, relationship dissatisfaction, and jealousy and irsha [4].

The few studies examining perpetration of Domestic Violence in India and other LMIPIs settings suggest Domestic Violence perpetration is associated with age, high socio-economic status, caste, religion, urban residence, accepting attitudes toward wife beating, childhood witness of Domestic Violence, aggression in the workplace or community, alcohol use, having multiple children, larger family dwelling (i.e. joint to joint families), marital duration, marital conflict (over sex and the male partner's infidelity), and failure of the wife to bring sufficient dowry. Strong patriarchal norms and the caste system also operate in Violence perpetration by men. There remains a large gap in exploring causes of Domestic Violence perpetration in low-income populations in LMIPIs settings where effects of poverty, stress, and powerlessness are amplified. As part of the formative work in developing a couples-based intervention for the secondary prevention of Domestic Violence in India, researcher explored potential determinants of Domestic Violence perpetration among recently-married men residing in slum communities' pharmaceutical institutions [5]. This is an important population in whom to study determinants of Domestic Violence because there is often minimal acquaintance pre-marriage, social dynamics and employment constraints heavily limit the time they spend together post marriage, crowding, poverty, and powerlessness likely further fuel Domestic Violence perpetration, and involvement by family members in the marriage is substantial (regardless of residence in joint versus nuclear families).

\section{Supporting information}

I express my sincere appreciation for all the attendee who shared their personal experiences and thoughts with our team. I thank other members of the Social and political category for their skilful, professional participant recruitment and conduct of interviews and entry and management of the data. Researcher thank the staff of the many non-teaching, mitra mandals, teachers, librarian for slum correlate pharmaceutical Institutions south west pune India, and nonteaching widow and widower staffs for their assistance with recruitment. Lastly, Researcher thank you for continued support of this work by Principal of low and middleincome pharmaceutical intuitions (LMIPIs) and the Indian Council of Medical Research.

\section{Acknowledgment}

This study has been guided under the unparallel supervision and guidance of Renowned Scientist Respected Dr. Ramesh Paranjape, Retd, Director and Scientist 'G' National AIDS Research Institute India. I express my sincere gratitude towards Sir for motivation and being great knowledge source for this work. I seek continuous support for my research career.

\section{Reference}

1. Rahul H (2018) Shocking Link of Rapid Rise in Pre-Cancer among the Healthy Adults in Pharmaceutical Institution Pune University India Living With Low Oxygen and Poor Sanitation Environment: Affordable Treatment Rate Three-Times Over. Glob J Add \& Rehab Med 5(5): 555673.

2. Rahul H (2018) Assessment of the Depression-level effectiveness of the Curse Words in Young Adults in Private Co-Educational Pharmaceutical Instituions in Pune University, India: A Preplanned, Causal-PathwayBased Analysis. Curr Tr Gatsr \& Hepatol 1(1)

3. Rahul H (2018) Two Trajectories. A Promise of Reform and Ashaaram Pattern. Degenerative Intellect Dev Disabil 1(3).

4. Rahul Hajare (2018) An Attempt to Eradicate Alcohol Dependency from Adult Men in Service Privately Managed Pharmaceutical Institutions in India. Toxi App Phar Insig 1(1).

5. Rahul Hajare (2018) The True Principal Health and Investigation of The High Burnout Stages Experienced by Professors Working in Pharmacy Institutions Pune University and Related Factors: an Important Study. Medical Research and Clinical Case Reports 1(2): 66-72.
Orthopedics and Sports Medicine Open Access Journal

DOI: 10.32474/OSMOAJ.2018.01.000112

\section{Assets of Publishing with us}

- Global archiving of articles

- Immediate, unrestricted online access

- Rigorous Peer Review Process

- Authors Retain Copyrights

- Unique DOI for all articles 